\title{
Tobacco Use and Tooth Loss among Adults Residing in Faridabad, Haryana, India
}

\author{
Sourav C Bidyasagar ${ }^{1}$, Charu M Marya ${ }^{2}$, Ruchi Nagpal ${ }^{3}$, Sakshi Kataria ${ }^{4}$, Pratibha Taneja ${ }^{5}$
}

\begin{abstract}
Background: Periodontal disease and dental caries are the most common causes of tooth loss among adults. Tobacco-related habits have also been identified as major behavioral risk factors for a variety of oral health-related conditions, such as periodontal diseases and tooth loss. Aim: To assess the association between tobacco use and tooth loss among adults aged 25 years and above in Faridabad district.

Materials and methods: The present study was a cross-sectional observational study. Data were collected through personal interviews and clinical examination. The clinical examination was conducted for the assessment of clinical variables, such as dentition status, according to WHO, Oral Health Survey: Basic Methods (2013), 5th edition. The data collected were entered in the Excel sheet using Microsoft Excel Software by the examiner. Data were analyzed using Statistics Package for Social Sciences (SPSS) version 21, IBM Inc. Inferential statistics was performed using the nonparametric tests, i.e., Mann-Whitney $U$ and Kruskal-Wallis tests.

Results: The maximum mean numbers of missing teeth were reported among only smokers (1.44), followed by only smokeless tobacco users (1.43), then both smokeless and smoked tobacco users (1.16), and least was reported by nonusers ( 0.21$)$. The maximum mean numbers of mobile teeth were reported among both smokeless and smoked tobacco users (2.16), followed by only smokers (2.14), and then only smokeless tobacco users (1.45). The least was reported by nonusers (0.51). On post hoc analysis for missing and mobile teeth, significant differences were seen. Conclusion: The tobacco-related habits were found to be significantly associated with both an increase in the mean tooth loss as well as mobility among the study participants.
\end{abstract}

Keywords: Smokers, Smokeless tobacco, Tobacco use, Tooth loss.

Journal of Oral Health and Community Dentistry (2019): 10.5005/jp-journals-10062-0044

\section{INTRODUCTION}

Among all these abused drugs, tobacco is the most widely distributed and commonly used drug. The social, economic, and political factors have contributed to the global spread of tobacco consumption. Tobacco smoking is one of the main causes of premature deaths globally. ${ }^{1}$ In 2010, an estimated 120 million Indian adults smoked, making India second only to China in number of smokers. ${ }^{2,3}$ Historically, most of the smoked tobacco in India has been in the form of bidis, small locally made cigarettes with tobacco wrapped inside a Tendu leaf. ${ }^{4}$

In 2010, smoking caused about 1 million deaths, or $10 \%$ of all deaths in India, with about $70 \%$ of these deaths occurring at the ages of 30-69 years. ${ }^{5,6}$ The patterns of use of bidis or manufactured cigarettes vary across different regions and socioeconomic levels. ${ }^{7,8}$

The consumption pattern of tobacco has likely changed over the last decade in response to substantially higher income in India paired with population growth and perhaps in response to modest tobacco-control efforts. ${ }^{9}$

Tooth loss is a consequence of accumulation over the course of an individual life times as a results of various causal factors that may be complex. ${ }^{10}$ The loss of many teeth often reduces the quality of life; embarrassment and self-consciousness limit social interaction and communication. Because of chewing problems and decreased masticatory function, a limitation in food selection may occur, resulting in nutritionally poor diets. Poor nutrition might contribute to an increased risk of several systemic diseases such as cardiovascular diseases and hypertension. Tooth loss may be a significant problem related to general health and the quality of life. ${ }^{11}$

\footnotetext{
${ }^{1-5}$ Department of Public Health Dentistry, Sudha Rustagi College of Dental Sciences and Research, Faridabad, Haryana, India

Corresponding Author: Sourav C Bidyasagar, Department of Public Health Dentistry, Sudha Rustagi College of Dental Sciences and Research, Faridabad, Haryana, India, Phone: +91 9811144408 , e-mail: generationx.sourav@gmail.com
}

How to cite this article: Bidyasagar SC, Marya CM, et al. Tobacco Use and Tooth Loss among Adults Residing in Faridabad, Haryana, India. J Oral Health Comm Dent 2019;13(2):50-53.

Source of support: Nil

Conflict of interest: None

Tobacco consumption both in smoking and smokeless forms is highly prevalent in India. Various studies have evaluated the effects of tobacco smoking on tooth loss in different populations; very little data are available regarding the effect of smokeless tobacco on tooth mortality. Smokers were found to demonstrate higher periodontal diseases and decayed missing and filled (DMF) scores, whereas in another longitudinal study, smokers were found to have the highest relative risk of losing teeth. ${ }^{12}$

Oral health is an integral part of general health and plays an important role in improving the quality of life. The oral cavity is the port of entry for many diseases and presents several unique features that make it especially prone to occupational diseases. Ramazzini, "the father of industrial hygiene," was the first to advocate the inclusion of the patient's occupation in medical history and to point out a number of oral symptoms. ${ }^{13}$

(-) The Author(s). 2019 Open Access This article is distributed under the terms of the Creative Commons Attribution 4.0International License (https://creativecommons. org/licenses/by-nc/4.0/), which permits unrestricted use, distribution, and non-commercial reproduction in any medium, provided you give appropriate credit to the original author(s) and the source, provide a link to the Creative Commons license, and indicate if changes were made. The Creative Commons Public Domain Dedication waiver (http://creativecommons.org/publicdomain/zero/1.0/) applies to the data made available in this article, unless otherwise stated. 
The dental literature reports that in cross-sectional studies, cigarette smoking has also been associated with higher prevalence of edentulousness and fewer remaining teeth and, in longitudinal studies, with increased rates of tooth loss. ${ }^{14,15}$

Taking all this in consideration, the present study was carried out to assess the association between tobacco use and tooth loss among adults aged 25 years and above in Faridabad district.

\section{Materials and Methods}

The present study was a cross-sectional observational study conducted to assess the relationship between tobacco use and tooth loss among adult population in Faridabad district. The study population included subjects 25 years of age and above reporting as outpatient to the Department of Public Health Dentistry, Sudha Rustagi College of Dental Sciences and Research, Faridabad. The examination was done on the patients with a wide range of oral findings. The convenience sampling technique was used to collect the data from various villages of Faridabad district. Total sample size was divided into 250 tobacco users and 250 nonusers to make the comparison.

\section{Inclusion Criteria}

- Subjects aged 25 years and above.

- Subjects living in Faridabad district, Haryana, since last 10 years.

- Subjects present on the day of examination.

- Subjects who were willing to participate after reading the information sheet and signing the informed consent.

\section{Exclusion Criteria}

- Physically challenged and mentally compromised elderly people and those with cognitive impairment were excluded.

- Elderly people with terminal illness were excluded.

- Patients who gave a history of discontinuing either or both the habits were excluded from the study.

The study protocol was approved by Institutional Ethical Committee, and ethical clearance was sought from the Ethical Committee of Sudha Rustagi College of Dental Sciences and Research, Faridabad, explaining the aim and importance of the study. Informed consent was obtained prior from each subject. The procedures followed were in accordance with the ethical standards of the responsible committee on human experimentation (institutional or regional) and with the Helsinki Declaration of 1975, as revised in 2000 .

\section{Method of Data Collection}

Data were collected through personal interview and clinical examination. The proforma used for the study was designed to include the important variables relevant for this study population.

\section{Personal Interview}

The information was obtained about the demographic variables (name, age, sex, address, education level, number of family members, total income of family), oral hygiene practices (types of cleaning aid used, method of cleaning, material used, frequency of cleaning or changing tooth brush), tobacco history of smoked tobacco (types of smoked tobacco, frequency of smoking, duration of smoking), and frequency of smokeless tobacco use (types of smokeless tobacco, frequency of smokeless tobacco use, duration of smokeless tobacco use).

Habit of tobacco use - the age of starting use of tobacco, form, and history of tobacco were recorded. Based on the habit of tobacco consumption, the study participants were divided into two groups: (1) tobacco users and (2) nonusers.

\section{Clinical Examination}

The clinical examination was conducted for the assessment of clinical variables, such as, dentition status, periodontal status [community periodontal index (CPI) modified], loss of attachment, and presence of oral mucosal lesions, according to WHO, Oral Health Survey: Basic Methods (2013), 5 th edition. ${ }^{19}$

Tooth loss pattern-in order to determine the pattern of tooth loss all, permanent molar are considered to be missing tooth if indicated for extraction because of decay reasons.

The examination was carried out in respective villages by making the person sit on a chair with a long back rest near the window under natural light. The examiner was standing by the side of the chair. The ADA-recommended Type III clinical examination was conducted with the aid of a plain mouth mirror and a Community Periodontal Index probe. The requisite number of sterilized instrument sets was taken to the site of the study. The strict sterilization and cross-infection preventive measures were adopted.

\section{Statistical Analysis}

The data collected were entered in the Excel sheet using Microsoft Excel Software by the examiner. Then, these data were transferred to Statistics Package for Social Sciences (SPSS) version 17, IBM Inc., for analysis. These were subjected to descriptive statistics for calculation of mean, standard deviation, frequencies, and percentages. The presentation of data was done using tables and graphs. The Chi-square test was used for comparison between categorical variables. The Shapiro-Wilk test was used to check whether the continuous variables were following normal distribution or not. As variables did not satisfy the condition of normal distribution, inferential statistics was performed using the nonparametric tests, i.e., Mann-Whitney $U$ (for comparing scores of two groups) and Kruskal-Wallis tests (for comparing scores of more than two groups). Level of statistical significance was set at $p$ value less than or equal to 0.05 .

\section{Results}

The present cross-sectional comparative study was conducted to assess the relationship of tobacco use and its effect on early tooth loss of adult population 25 years and above in Faridabad district. The study consisted of 250 tobacco users and nonusers each.

The age-wise and gender-wise distribution of study population among tobacco users and tobacco nonusers was compared using the Chi-square test. It was found to be significant with maximum tobacco users among 35-44 years age group and least in 45 years and above and among males than females, respectively (Table 1 ).

The age-wise and gender-wise distribution of study population among different subgroups was compared using the Chi-square test. It was found to be significant. The nonusers were found to be significantly more among 25-34 years age group as compared to other age groups and more among males than females (Table 2). 
Table 1: Age-wise and gender-wise distribution of study population among tobacco users and nonusers

\begin{tabular}{|c|c|c|c|c|}
\hline \multirow[b]{2}{*}{ Age groups } & & \multicolumn{2}{|c|}{ Groups } & \multirow{2}{*}{$\begin{array}{l}\text { Chi-square } \\
\text { test } \\
(p \text { value })^{a}\end{array}$} \\
\hline & & Tobacco users & $\begin{array}{l}\text { Tobacco } \\
\text { nonusers }\end{array}$ & \\
\hline \multirow[t]{2}{*}{$25-34$ years } & $N$ & 94 & 133 & $0.0001^{*}$ \\
\hline & $\%$ & 41.2 & 58.5 & \\
\hline \multirow[t]{2}{*}{$35-44$ years } & $N$ & 108 & 90 & \\
\hline & $\%$ & 54.6 & 45.4 & \\
\hline \multirow[t]{2}{*}{45 years and above } & $N$ & 48 & 27 & \\
\hline & $\%$ & 64 & 36 & \\
\hline \multirow[t]{2}{*}{ Male } & $N$ & 240 & 217 & $0.0001^{*}$ \\
\hline & $\%$ & 52.5 & 47.5 & \\
\hline \multirow[t]{2}{*}{ Female } & $N$ & 10 & 33 & \\
\hline & $\%$ & 23.3 & 76.7 & \\
\hline
\end{tabular}

${ }^{a}$ Chi-square test, ${ }^{*}$ significance of relationship at $p<0.05$

The mean numbers of mobile teeth and missing teeth were reported significantly higher among nonusers (Table 3 ).

The mean numbers of missing teeth were found to be significant. The maximum was reported among only smokers (1.44), followed by only smokeless tobacco users (1.43), then both smokeless and smoked tobacco users (1.16), and least was reported among nonusers (0.21). On post hoc (pair-wise) analysis, significant differences were seen between only smokers and nonusers and also between only smokeless tobacco users and nonusers. The mean numbers of mobile teeth were found to be significant. The maximum was reported among both smokeless and smoked tobacco users (2.16), followed by only smokers (2.14), and then only smokeless tobacco users (1.45). The least was reported among nonusers (0.51). On post hoc (pair-wise) analysis, significant differences were seen between only smokers and nonusers and also between both smokeless and smoked tobacco users and nonusers (Table 4).

\section{Discussion}

Tobacco use is a major public health threat globally. It is one of the major risk factors not only for chronic diseases, including cancer, lung diseases, and cardiovascular diseases, but also for oral mucosal lesions and periodontal diseases. Periodontitis is associated with coronary heart disease and diabetes mellitus. ${ }^{2,6}$

In India, the habit of smokeless tobacco use is highly prevalent in various regions of the country. This habit is culturally ingrained among the population and is generally considered to be a part of the lifestyle. There is also a general belief that smokeless tobacco is less harmful than smoking. Moreover, people believe that chewing tobacco can provide relief from dental complaints such as pain and halitosis. On account of these beliefs, the habit is widespread among Indians, and hence, the dental effects of such habits may be more prevalent in this population. ${ }^{16-18}$

Henceforth, this present study was carried out to evaluate the relationship of tobacco use and its effect on early tooth loss of adult population 25 years and above in Faridabad district.

Irrespective of the tobacco-related habits, in the present study, an increase both in the prevalence and mean tooth loss among the study participants was observed with advancing age. This trend is in accordance with the generally observed pattern of higher tooth loss associated with advancing age.

In the present study, among 25-34 years age group, 94 (41.2\%) were tobacco users and 133 (58.6\%) were tobacco nonusers. Among 35-44 years age group, 108 (54.6\%) were tobacco users and 90 $(45.4 \%)$ were tobacco nonusers. Among 45 years and above age group, 48 (64\%) were tobacco users and 27 (36\%) were tobacco nonusers. It was found to be significant with maximum tobacco users among 35-44 years age group and least in 45 years and above. It was similar to that reported by Anand et al. ${ }^{19}$ and Subramanian et al. ${ }^{4}$ in their study. Majority of subjects used smokeless tobacco.

Among males, 240 (52.5\%) were tobacco users and 217 (47.5\%) were tobacco nonusers. Among 43 (9.6\%) females, 10 (23.3\%) were tobacco users and $33(76.7 \%)$ were tobacco nonusers. Tobacco users were found to be significantly more among males than females. It was dissimilar to that reported by Anand et al. ${ }^{19}$ in their study. The predominance of men using tobacco in these studies may be justified by the greater requirement of men in the industrial sector since many activities require physical strength or involve manual labor. The only study in which there were a higher proportion of women compared to men was conducted in two chocolate factories in which the type of activity explains the predominance of women.

In the present study, mean numbers of mobile teeth and missing teeth were found to be statistically significant $(p<0.001)$.

Table 2: Age-wise and gender-wise distribution of study population among tobacco users and nonusers

\begin{tabular}{|c|c|c|c|c|c|c|}
\hline \multirow[b]{2}{*}{ Age groups } & & \multicolumn{4}{|c|}{ Groups } & \multirow{2}{*}{$\begin{array}{l}\text { Chi-square } \\
\text { test } \\
(p \text { value })^{a}\end{array}$} \\
\hline & & Nonusers & Only smokers & $\begin{array}{l}\text { Only smokeless } \\
\text { tobacco }\end{array}$ & $\begin{array}{l}\text { Both smokeless } \\
\text { and smoked }\end{array}$ & \\
\hline \multirow[t]{2}{*}{$25-34$ years } & $N$ & 133 & 62 & 20 & 12 & $0.0001^{*}$ \\
\hline & $\%$ & 58.6 & 27.3 & 8.8 & 5.3 & \\
\hline \multirow[t]{2}{*}{$35-44$ years } & $N$ & 90 & 79 & 15 & 14 & \\
\hline & $\%$ & 45.5 & 39.9 & 7.6 & 7.1 & \\
\hline \multirow[t]{2}{*}{45 years and above } & $N$ & 27 & 33 & 9 & 6 & \\
\hline & $\%$ & 36.0 & 44.0 & 12.0 & 8.0 & \\
\hline \multirow[t]{2}{*}{ Male } & $N$ & 217 & 173 & 36 & 31 & $0.0001^{*}$ \\
\hline & $\%$ & 47.5 & 37.9 & 7.9 & 6.8 & \\
\hline \multirow[t]{2}{*}{ Female } & $N$ & 33 & 1 & 8 & 1 & \\
\hline & $\%$ & 76.7 & 2.3 & 18.6 & 2.3 & \\
\hline
\end{tabular}

${ }^{a}$ Chi-square test, ${ }^{*}$ significance of relationship at $p<0.05$ 
Table 3: Mean (SD) of number of mobile teeth among study population

\begin{tabular}{llll}
\hline Groups & & Mean & Std. deviation \\
\hline $\begin{array}{lll}\text { No. of mobile } \\
\text { teeth }\end{array}$ & Tobacco users & 2.02 & 3.339 \\
& $\begin{array}{l}\text { Tobacco non- } \\
\text { users }\end{array}$ & 0.51 & 1.535 \\
$\begin{array}{l}\text { No. of missing } \\
\text { teeth }\end{array}$ & Tobacco users & 1.40 & 2.966 \\
& $\begin{array}{l}\text { Tobacco non- } \\
\text { users }\end{array}$ & 0.21 & 0.796 \\
\hline
\end{tabular}

Table 4: Mean (SD) of number of missing teeth among population subgroups

\begin{tabular}{lllll}
\hline & & Mean & Std. deviation & p value \\
\hline No. of missing teeth & & & \\
1 & Nonusers & 0.21 & 0.79 & $0.0001,2>$ \\
2 & Only smokers & 1.44 & 2.50 & $1,3>1$ \\
3 & $\begin{array}{l}\text { Only smokeless } \\
\text { tobacco }\end{array}$ & 1.43 & 4.86 & \\
4 & $\begin{array}{l}\text { Both smokeless } \\
\text { and smoked }\end{array}$ & 1.16 & 1.68 & \\
No. of mobile teeth & & & $0.0001,1<$ \\
1 & $\quad$ Nonusers & 0.51 & 1.53 & 2,4 \\
2 & $\begin{array}{l}\text { Only smokers } \\
3\end{array}$ & 2.14 & 3.66 & \\
& $\begin{array}{l}\text { Only smokeless } \\
\text { tobacco }\end{array}$ & 1.45 & 2.29 & \\
4 & $\begin{array}{l}\text { Both smokeless } \\
\text { and smoked }\end{array}$ & 2.16 & 2.57 & \\
\hline
\end{tabular}

It was similar to that reported by Anand et al. ${ }^{19}$ and also Albandar et al. ${ }^{5}$ These findings reinforce the fact that smoking has significant effect on periodontal health. These patients often tend to visit the dental clinic with the objective of immediate or early pain relief and hence prefer extraction rather than any curative treatments.

\section{ConcLusion}

The tobacco-related habits were found to be significantly associated with both mean tooth loss as well as mobility among the study participants.

\section{LiMITATIONS}

Nonetheless, the study also had several limitations. First, this study represents findings of a smaller sample size. Nationwide studies need to be conducted to throw a better light in this direction as oral cancer is one of the leading causes of death. Second, studies need to be conducted evaluating different varieties of smokeless and smoked form. Third, data on tobacco use were collected based on the survey participants' self-reported information. This carries an inherent potential for memory bias.
Fourth, different arches, i.e., maxillary and mandibular, can be considered separately.

\section{References}

1. Bhawna G. Burden of smoked and smokeless tobacco consumption in India-results from the global adult tobacco survey India (GATSIndia)-2009-2010. Asian Pac J Cancer Prev 2013;14(5):323-329. DOI: 10.7314/APJCP.2013.14.5.3323.

2. Forslund $H B$, Lindroos $A K$, et al. Number of teeth, body mass index, and dental anxiety in middle-aged Swedish women. Acta Odontol Scand 2002;60:346-352. DOI: 10.1080/000163502762667379.

3. Benguigui $C$, Bongard V, et al. Evaluation of oral health related to body mass index. Oral Diseases 2012;18:748-755. DOI: 10.1111/j.16010825.2012.01940.x.

4. Subramanian SV, Nandy S, et al. Patterns and distribution of tobacco consumption in India: cross sectional multilevel evidence from the 1998-9 national family health survey. BMJ 2004;328:801-806. DOI: 10.1136/bmj.328.7443.801.

5. Albandar JM, Streckfus CF, et al. Cigar, pipe, and cigarette smoking as risk factors for periodontal disease and tooth loss. J Periodontol 2000;71(12):1874-1881. DOI: 10.1902/jop.2000.71.12.1874.

6. Ostberg A-L, Bengtsson C, et al. Oral health and obesity indicators. BMC Oral Health 2012;12:50. DOI: 10.1186/1472-6831-12-50.

7. Prpic J, Kuis D, et al. Obesity and oral health: is there an association? Coll Antropol 2012;36:755-759.

8. Johansson I, Tidehag P, et al. Dental status, diet and cardiovascular risk factors in middle-aged people in northern Sweden. Community Dent Oral Epidemiol 1994;22:431-436. DOI: 10.1111/j.1600-0528.1994. tb00792.x.

9. Kaur G, Holtfreter B, et al. Association between type 1 and type 2 diabetes with periodontal disease and tooth loss. J Clin Periodontol 2009;36:765-774. DOI: 10.1111/j.1600-051X.2009.01445.x.

10. Hanioka T, Ojima M, et al. Association of total tooth loss with smoking, drinking alcohol and nutrition in elderly Japanese: analysis of national database. Gerodontology 2007;24:87-92. DOI: 10.1111/j.17412358.2007.00166.x.

11. Miki O, Takashi $\mathrm{H}$, et al. Cigarette smoking and tooth loss experience among young adults: a national record linkage study. BMC Public Health 2007;7:313. DOI: 10.1186/1471-2458-7-313.

12. Hamasha A, Sasa I, et al. Risk indicators associated with tooth loss in Jordanian adults. Community Dent Oral Epidemiol 2000;28(1): 67-72. DOI: 10.1034/j.1600-0528.2000.280109.x.

13. Schour I, Samat BG. Oral manifestations of occupational origin. J Am Med Assoc 120:1197-1207. DOI: 10.1001/jama.1942.02830500027009.

14. Dietrich T, Maserejian N, et al. Tobacco use and incidence of tooth loss among US male health professionals. J Dent Res 2007;86(4):373-377. DOI: $10.1177 / 154405910708600414$.

15. Deborah M. Tobacco Use and Oral Disease. J Dent Educ 2001;65(4): 306-312.

16. Holm G. Smoking as an additional risk for tooth loss. J Periodontol 1994;65(11):996-1001. DOI: 10.1902/jop.1994.65.11.996.

17. Locker D, Ford J, et al. Incidence of and risk factors for tooth loss in a population of older Canadians. J Dent Res 1996;75(2):783-789. DOI: 10.1177/00220345960750020801.

18. Krall EA, Dawson-Hughes $B$, et al. Smoking, smoking cessation, and tooth loss. J Dent Res 1997;76(10):1653-1659. DOI: $10.1177 / 00220345970760100601$.

19. Anand S, Kavitha P, et al. Relationship of Smoking and Smokeless Tobacco Use to Tooth Loss in a Central Indian Population. Oral Health Prev Dent 2012;10(3):243-252. 